\section{(A) Check for updates}

Cite this: Dalton Trans., 2018, 47 2086

Received 7th November 2017, Accepted 13th December 2017 DOI: $10.1039 / c 7 d t 04201 a$ rsc.li/dalton

\title{
Sky-blue emitting bridged diiridium complexes: beneficial effects of intramolecular $\pi-\pi$ stacking $\dagger$
}

\author{
Daniel G. Congrave, (D) Yu-Ting Hsu, Andrei S. Batsanov, Andrew Beeby and \\ Martin R. Bryce (D)*
}

\begin{abstract}
The potential of intramolecular $\pi-\pi$ interactions to influence the photophysical properties of diiridium complexes is an unexplored topic, and provides the motivation for the present study. A series of diarylhydrazide-bridged diiridium complexes functionalised with phenylpyridine (ppy)-based cyclometalating ligands is reported. It is shown by NMR studies in solution and single crystal X-ray analysis that intramolecular $\pi-\pi$ interactions between the bridging and cyclometalating ligands rigidify the complexes leading to high luminescence quantum efficiencies in solution and in doped films. Fluorine substituents on the phenyl rings of the bridge promote the intramolecular $\pi-\pi$ interactions. Notably, these non-covalent interactions are harnessed in the rational design and synthesis of the first examples of highly emissive sky-blue diiridium complexes featuring conjugated bridging ligands, for which they play a vital role in the structural and photophysical properties. Experimental results are supported by computational studies.
\end{abstract}

\section{Introduction}

Iridium(III) complexes possess rich metal-ligand based photochemistry, typically with high luminescence quantum efficiency $(\Phi)$ and short excited state lifetimes $\left(\tau_{\mathrm{p}}\right)$. They are widely employed in applications ${ }^{1}$ such as photocatalysis, ${ }^{2}$ biological labelling, ${ }^{3}$ sensing $^{4}$ and as emissive dopants in phosphorescent organic light-emissive devices (PhOLEDs). ${ }^{5,6}$ Their emission colour can be tuned across the entire visible spectrum by systematic variation of the ligands. ${ }^{7}$

Unlike their monometallic analogues, diiridium complexes are rarely studied for luminescence applications due to their generally low photoluminescence quantum yields (PLQYs) and limited colour range. ${ }^{8-17}$ However, there are examples where the favourable luminescent properties of monoiridium complexes are retained in diiridium complexes by the careful choice of conjugated bridging ligands. ${ }^{18-27}$ Moreover, bridging ligands offer scope for increased structural variation compared to monoiridium analogues, and allow tuning of the electronic communication between the iridium centres which may lead to interesting photophysical properties, such as improved spin-orbit coupling effects, ${ }^{24,26}$ or dual emission. Diiridium

Department of Chemistry, Durham University, South Road, Durham DH1 3LE, UK. E-mail:m.r.bryce@durham.ac.uk

$\dagger$ Electronic supplementary information (ESI) available: Synthetic details, NMR spectra, X-ray data, electrochemistry, thermal gravimetric analysis; computations and photophysics. CCDC 1576081-1576084 and 1576093-1576095. For ESI and crystallographic data in CIF or other electronic format see DOI: 10.1039/ c7dt04201a complexes are known with efficient emission from red to green $;{ }^{18-26}$ however, we are not aware of any blue/sky-blue diiridium complexes featuring conjugated bridging ligands. ${ }^{28}$

Recently, we described diarylhydrazide-bridged diiridium complexes functionalised with phenylpyridine (ppy)-based cyclometalating ligands. ${ }^{22}$ These complexes are highly emissive in the green region when doped into rigid poly(methylmethacrylate) (PMMA) films, but are practically nonemissive in solution, presumably due to the flexibility of their non-ancillary bridging units which leads to non-radiative decay via intramolecular motion. An interesting structural feature was observed: the pendant aryl rings on the bridge engage in intramolecular face-to-face $\pi-\pi$ stacking with the cyclometalating phenyl ligands in the solid state (complex 1, Fig. 1).

Intramolecular $\pi-\pi$ stacking between aryl and heteroaryl rings has been reported in a few specific monoiridium complexes (e.g. 2-6, Fig. 1), particularly in charged derivatives. ${ }^{29-33}$ For example, in complex 2 intramolecular $\pi-\pi$ stacking between a cyclometalating ligand and a pendant pentafluorophenyl group leads to an order of magnitude increase in solution PLQY, due to a reduction in the non-radiative rate constant $\left(k_{\mathrm{nr}}\right) \cdot{ }^{31}$ Intramolecular $\pi-\pi$ stacking in complex 3 leads to increased operational stability of light-emitting electrochemical cells (LEECs). ${ }^{29}$ Nonetheless, the potential of intramolecular $\pi-\pi$ interactions to influence the photophysical properties of diiridium complexes remains unexplored, and provides the motivation for the present study.

We now show that intramolecular $\pi-\pi$ stacking can be exploited to rigidify diiridium complexes and to obtain high luminescence quantum efficiencies in solution and in doped 

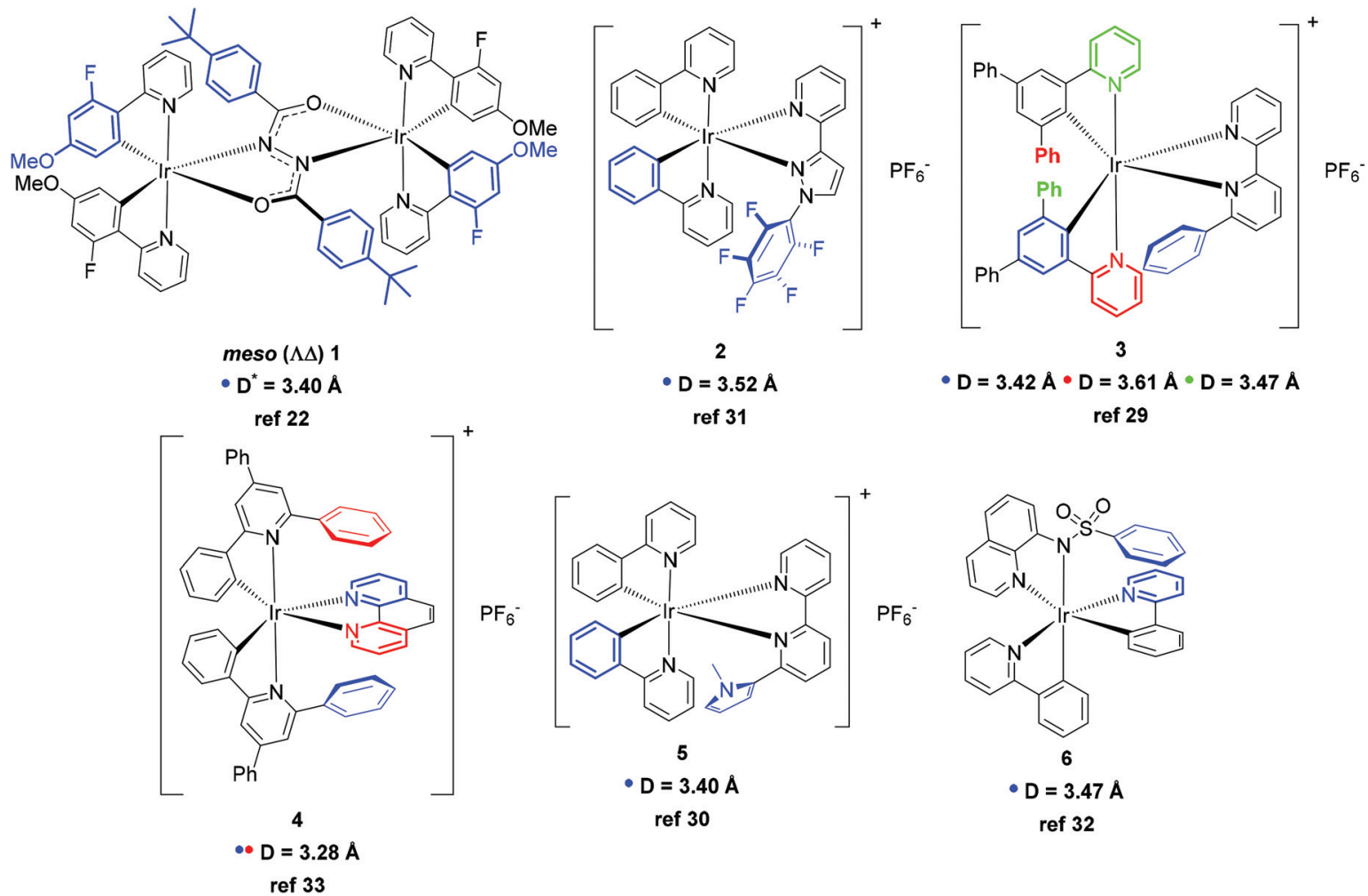

Fig. 1 Representative iridium complexes which display intramolecular $\pi-\pi$ stacking interactions, highlighted by the coloured rings. $D=$ centroidcentroid distance determined by X-ray diffraction for the same-coloured rings. $D^{*}=$ distance between the centroid of the bridge aryl ring and the plane of the cyclometalating ligand.

films. We also present the first examples of highly emissive sky-blue diiridium complexes featuring conjugated bridging ligands, for which the $\pi-\pi$ interactions play an important role in the structural and photophysical properties.

\section{Results and discussion}

\section{Design, synthesis and characterisation}

The structural versatility of $\mathbf{1}$ and analogues ${ }^{22}$ provides an ideal opportunity to explore how intramolecular $\pi-\pi$ interactions between the bridging and cyclometalating ligands can influence the photophysical properties of diiridium systems. Benzene is well known to stack with hexafluorobenzene in a slipped face-to-face configuration in the solid state. ${ }^{34-36}$ Complexes 7-9 (Fig. 2) with an increasing number of fluorine substituents on the phenyl rings of the bridge, were, therefore, designed with the aim of promoting intramolecular $\pi-\pi$ interactions. Methoxy derivative $\mathbf{1 0}$ was also included based on calculations (discussed below) which predict the bridge of $\mathbf{1 0}$ to be non-ancillary despite the highly fluorinated aryl rings (in contrast to 8 and 9). The analogues 12 and 14, featuring $\mathrm{CF}_{3}$ substituents instead of perfluoroaryl rings, were studied as model compounds for which $\pi-\pi$ interactions involving the bridge are not possible. For derivatives 11-15, the substituents on the pyridyl rings serve to enhance solubi- lity. For 13-15 the difluorophenyl rings of the ppy ligands were chosen to blue shift the emission, based on monoiridium precedents. $^{37,38}$

The diarylhydrazide bridges 17a-d (Fig. 2) were synthesised (Scheme $\mathrm{S} 1 \dagger$ ) by condensation of hydrazine monohydrate with the corresponding benzoyl chlorides, which were either commercially available or prepared from the corresponding benzoic acid (16a-d). The bridge units were heated in a $1: 1$ molar ratio with $\left[\operatorname{Ir}(\mathrm{ppy})_{2} \mu-\mathrm{Cl}\right]_{2}$ in either 2-ethoxyethanol (17a) or dry diglyme $(\mathbf{1 7 b}-\mathbf{d})$ in the presence of $\mathrm{K}_{2} \mathrm{CO}_{3}$, to obtain the complexes $\mathbf{7 - 1 0}$ as diastereomeric mixtures (meso $\Lambda \Delta$ and $\operatorname{rac} \Lambda \Lambda / \Delta \Delta$ ) (Fig. 2). In previous investigations, the diastereomers of analogous phenylpyridine-functionalised diiridium systems were separated and minimal differences were observed in the photophysical properties of the two diastereomers. $^{21,22}$ Therefore, complexes 7-10 were characterised as diastereomeric mixtures. The complexes were unambiguously identified by ${ }^{1} \mathrm{H},{ }^{19} \mathrm{~F}$ and ${ }^{13} \mathrm{C}$ (where solubility allowed) NMR spectroscopy, MALDI-TOF mass spectrometry and elemental analysis. NMR peak assignments were aided by ${ }^{1} \mathrm{H}-{ }^{1} \mathrm{H}$ COSY, ${ }^{1} \mathrm{H}-{ }^{1} \mathrm{H}$ NOESY, ${ }^{1} \mathrm{H}-{ }^{1} \mathrm{H}$ ROESY, ${ }^{1} \mathrm{H}-{ }^{13} \mathrm{C}$ HSQC, ${ }^{1} \mathrm{H}-{ }^{13} \mathrm{C}$ HMBC and ${ }^{19} \mathrm{~F}-{ }^{19} \mathrm{~F}$ COSY $2 \mathrm{D}$ NMR experiments.

For complexes $\mathbf{7 - 1 0}$ the ${ }^{19} \mathrm{~F}$ NMR data are of particular interest. For the bis(difluorophenyl)hydrazide-bridged complex 7, a single peak is observed in the ${ }^{19} \mathrm{~F}$ spectrum of the diastereomeric mixture (Fig. $\mathrm{S} 2 \dagger$ ), analogous to the spectrum 

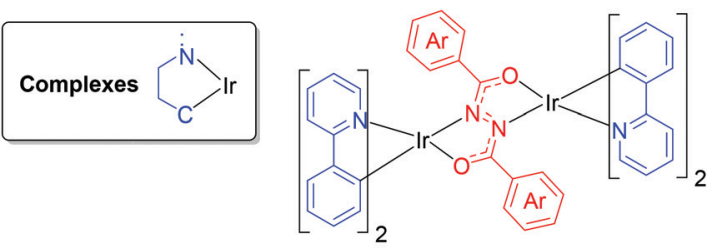<smiles>Fc1cc(F)cc(I)c1</smiles><smiles>CC(C)(C)c1c(F)c(F)c(F)c(F)c1F</smiles><smiles>COc1c(F)c(F)c(F)c(C(C)(O)I)c1F</smiles>

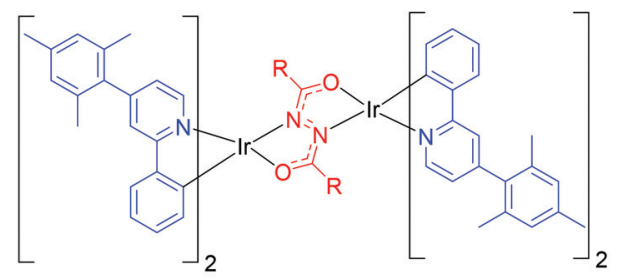

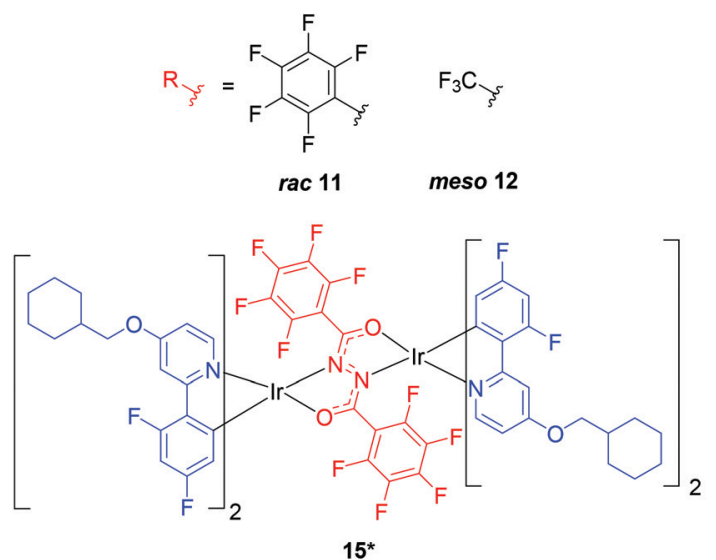

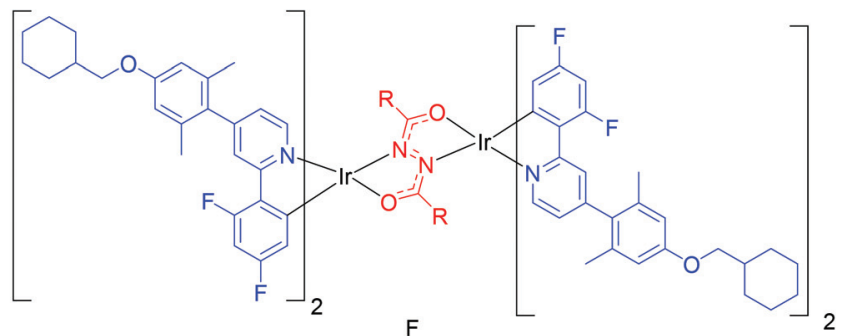<smiles>[R][C]=C(F)c1c(F)c([Y])c(F)c(F)c1F</smiles>

meso and rac separate
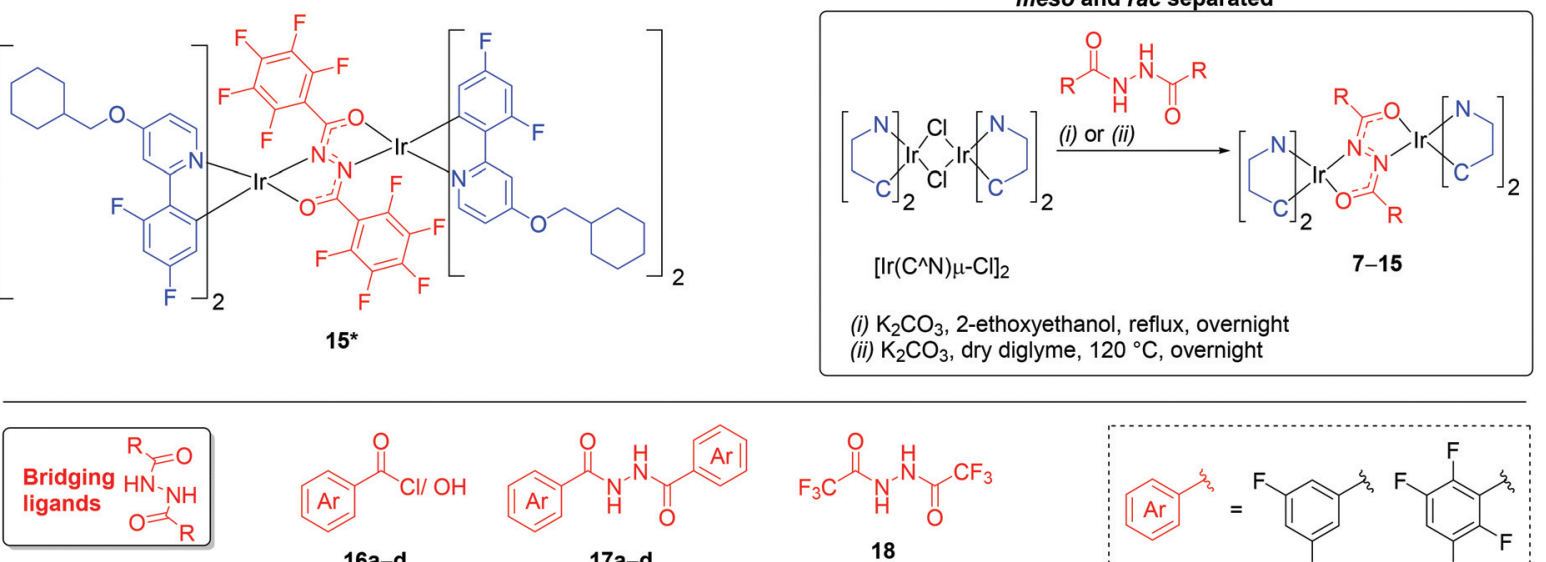

$16 a-d$

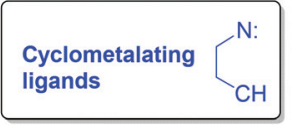

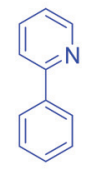

19<smiles>O=C(NNC(=O)C(F)(F)F)c1ccccc1</smiles>

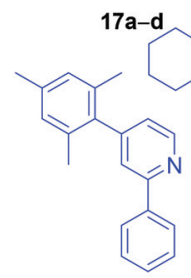

20

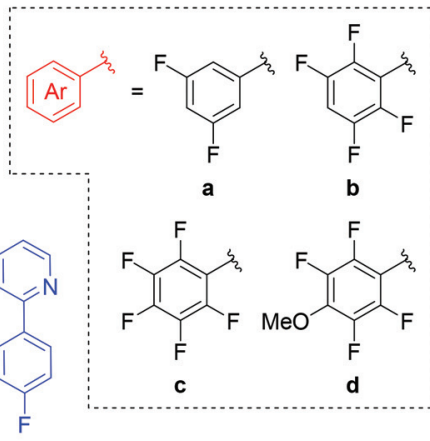

22

Fig. 2 (Top) Structures for the diiridium complexes studied in this work. (Bottom) Structures for the bridging and cyclometalating ligands. Complexes were studied as diastereomeric mixtures unless otherwise stated. * Complexes 14 and 15 were isolated as single diastereomers; their absolute configurations are unknown.

of the free bridge (17a) (Fig. S74†). This indicates that the ${ }^{19} \mathrm{~F}$ environments are very similar for each diastereomer of 7 and that the bridging phenyl rings are freely rotating in solution on the NMR timescale.

This contrasts with the data for the bis(pentafluorophenyl) hydrazide-bridged complex $\mathbf{9}$. The ligand $17 \mathrm{c}$ features 3 distinct environments in its ${ }^{19} \mathrm{~F}$ NMR spectrum as expected (Fig. S80 $\dagger$ ), whereas the ${ }^{19} \mathrm{~F}$ NMR spectrum of meso 9 features 5 well-resolved distinct environments (Fig. 3 and Fig. S15†) due to an apparent breakdown in symmetry, suggesting that rotation of the bridging pentafluorophenyl rings is restricted at room temperature in solution. This was confirmed when meso 9 was further studied by ${ }^{19} \mathrm{~F}^{19} \mathrm{~F}$ COSY NMR (Fig. 3). This is because, although only ortho $\left({ }^{3} J \approx 23 \mathrm{~Hz}\right)$ and para $\left({ }^{5} \mathrm{~J} \approx 6 \mathrm{~Hz}\right)$ couplings are observed (in agreement with the multiplicities of the signals in the $1 \mathrm{D}$ spectrum), the data indicate that all 5 fluorine environments are on the same ring. $\operatorname{meta}\left({ }^{4} J\right){ }^{19} \mathrm{~F}-{ }^{19} \mathrm{~F}$ coupling constants that are considerably smaller than those for ortho and para coupling (or even absent) have been commonly reported for heavily fluorinated aryl systems. ${ }^{39-43}$ It has been suggested that this is because $\pi$-conjugation contributes significantly to ${ }^{19} \mathrm{~F}-{ }^{19} \mathrm{~F}$ coupling in aromatics..${ }^{39,43}$ 


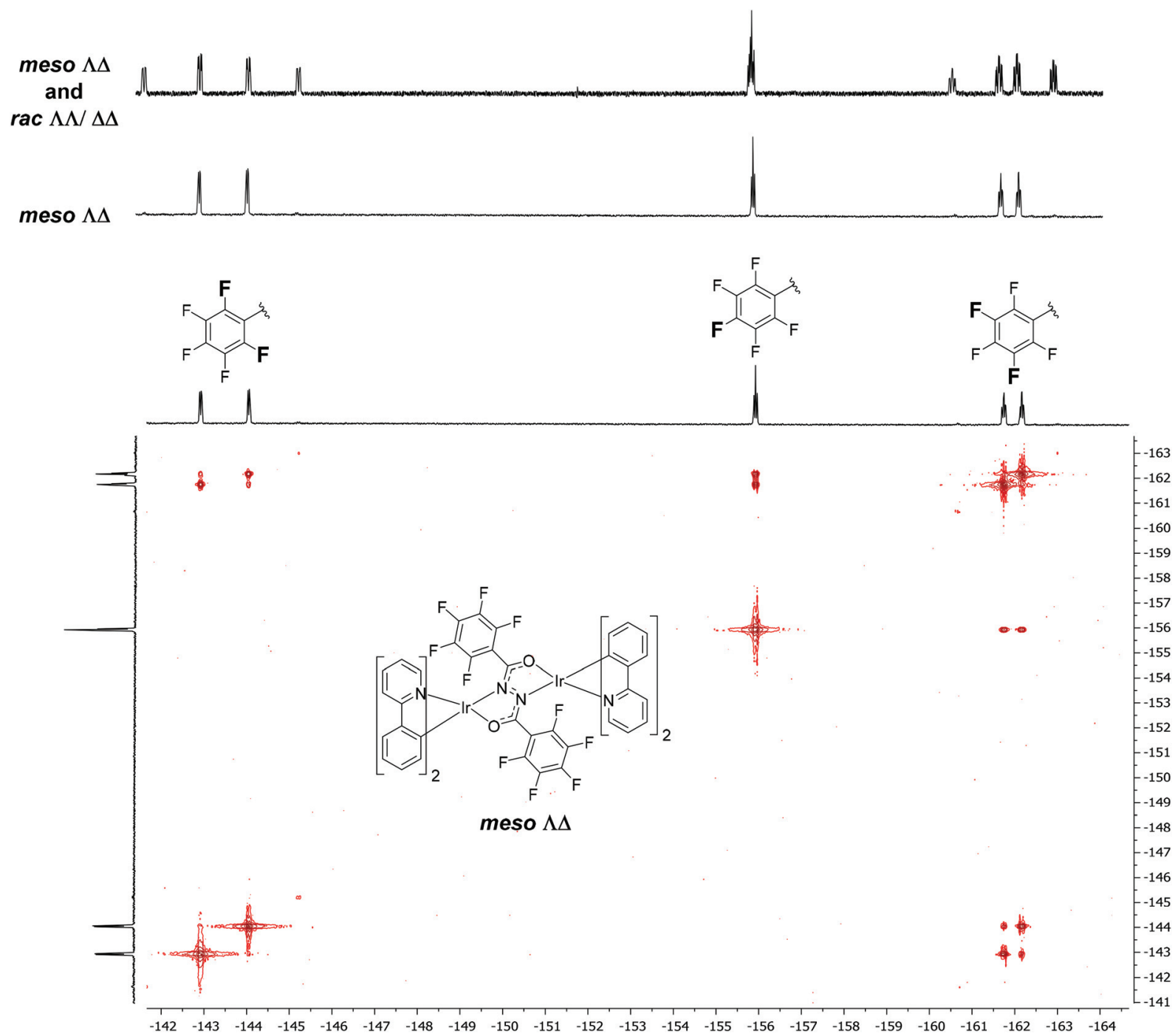

Fig. 3 (Top) ${ }^{19} \mathrm{~F}$ NMR spectrum of the diastereomeric mixture of 9 (ca. $5: 4$ molar ratio of meso $(\Lambda \Delta)$ and rac $(\Lambda \Lambda / \Delta \Delta)$ ). $\left(\right.$ Middle) ${ }^{19} \mathrm{~F} \mathrm{NMR} \mathrm{spectrum}$ of meso 9. (Bottom) ${ }^{19} \mathrm{~F}-{ }^{19} \mathrm{~F}$ COSY NMR spectrum of meso 9 . Chemical shifts are in ppm.

We propose that this restriction of rotation is due to intramolecular $\pi-\pi$ interactions. Steric restriction alone is unlikely to explain such well-resolved ${ }^{19} \mathrm{~F}$ NMR signals, considering that fluorine atoms exert similar steric effects as protons, ${ }^{44}$ and that the analogous difluoro complex 7 does not exhibit this effect. The ${ }^{19} \mathrm{~F}$ NMR spectra of complexes 8, 10, 11, 13 and 15 also show this feature (Fig. S5, S18, S24, S42, S51 and S68†). These observations indicate that a bridge tetrafluorophenyl group is sufficient to promote strong intramolecular $\pi-\pi$ interactions in solution, and that fluorine atoms on the cyclometalating phenyl rings of ppy ligands (13 and 15) do not suppress them.

The bis(trifluoromethyl) bridge $\mathbf{1 8}^{45}$ (Fig. 2) was also investigated, as although it is strongly electron withdrawing like the perfluoroaryl bridge 17c, ${ }^{46}$ it cannot engage in intramolecular $\pi-\pi$ stacking. Attempts to isolate a complex analogous to 9 by reacting the bridge 18 with $\left[\operatorname{Ir}(\mathrm{ppy})_{2} \mu-\mathrm{Cl}\right]_{2}$ were unsuccessful, due to its extremely poor solubility (mass spectra suggested the complex had formed). As an alternative, complex 12 was synthesised (Fig. 2), which features 4-mesityl-2-phenylpyridine (20) cyclometalating ligands. Mesityl groups are known to improve the solubility of cyclometalated iridium complexes while exerting minimal influence on their photophysical properties. ${ }^{47-49}$ Complex 12 was isolated as a diastereomerically pure meso sample (confirmed by X-ray diffraction, Fig. S102 $\dagger$ ) in $61 \%$ yield. No rac diastereomer was detected in the crude reaction mixture. This stereoselectivity is surprising as DFT calculations predict the rac diastereomer to be the more thermodynamically stable, as is usually the case for diiridium systems. ${ }^{21,22,50}$ Attempts to isomerise 12 thermally or photochemically were unsuccessful, as previously reported for other diiridium diastereomers. ${ }^{22}$

To allow a direct comparison with complex 12, complex 11 (the mesityl-functionalised analogue of complex 9) (Fig. 2), was also synthesised. Interestingly, the presence of mesityl groups leads to a larger difference in the solubilities of the diastereomers of $\mathbf{1 1}$ compared to $\mathbf{9}$, making them trivial to separ- 
ate by column chromatography. However, the extremely poor solubility of meso $\mathbf{1 1}$ prevented its purification and so only rac $\mathbf{1 1}$ is studied here (stereochemistry confirmed by X-ray diffraction, Fig. S101†). It is noteworthy that meso $\mathbf{1 1}$ is less soluble than complex 9 despite the presence of mesityl groups, in contrast to the expectation based on previous reports. ${ }^{47,48,50}$ A tentative explanation is based on the symmetry of the complex. ${ }^{51}$

We have previously shown that colour tuning of the emission of diarylhydrazide-bridged diiridium complexes within the range $\lambda_{\max } 520-490 \mathrm{~nm}$ can be achieved through functionalisation of either the bridge or cyclometallating phenyl rings with electron withdrawing groups. ${ }^{21,22}$ We reasoned, therefore, that simultaneous functionalisation of both moieties with electron withdrawing groups might afford blue/sky-blue diiridium complexes, which to date remain elusive.

Initial attempts to obtain diiridium complexes through a combination of 2-(2,4-difluorophenyl)pyridine (dfppy) or 2-(2,4-difluorophenyl)-4-mesitylpyridine ${ }^{48}$ with the bis(pentafluorophenyl)/(trifluoromethyl) bridges 17 c and 18 (Fig. 2) were unsuccessful due to the extremely poor solubility of the products. To enhance solubility the new dfppy derivative 21 (Fig. 2) was synthesised (Scheme S1†), wherein the mesityl group is replaced by a methylenecyclohexylether-functionalised xylyl group. The methylenecyclohexyl group provides the beneficial solubilising properties of a branched alkyl group while being achiral. Additionally, the xylyl spacer in $\mathbf{2 1}$ is a rigid non-conjugated linker to limit the electronic influence of the electron-donating ether group. The ligand 22 (Fig. 2) was also synthesised (Scheme S1†) to investigate the effect of directly functionalising the pyridyl moiety with the methylenecyclohexylether group, which is expected to destabilise the lowest unoccupied molecular orbital (LUMO) and further blue shift emission.

As observed for 12, the bis(trifluoromethyl) bridge 18 resulted in only a single diastereomer for complex 14 (Fig. 2). These two examples (12 and 14) suggest that bis(alkyl)hydrazide bridges afford diiridium complexes from racemic $\mu$-dichloro dimers without the formation of diastereomeric mixtures. This is complementary to using enantiomerically pure dichloro-bridged dimers, as reported for other systems. ${ }^{49,52}$
Analogous to the mesityl-functionalised complex 11, the diastereomers rac $\mathbf{1 3}$ (stereochemistry confirmed by X-ray diffraction, Fig. 4) and meso 13 were easily separated. The improved solubility imparted by the methylenecyclohexylether groups allowed both diastereomers to be fully characterised. Complex $\mathbf{1 5}$ was isolated as a single diastereomer: the absolute configuration is unknown, although it is probably the meso structure from inspection of the ${ }^{1} \mathrm{H}$ NMR spectrum (Fig. S66†). A second diastereomer was observed by NMR but could not be isolated.

Thermal gravimetric analysis (TGA) shows that all the complexes 7-15 possess good thermal stability (Fig. S144-S153†).

\section{X-Ray molecular structures}

Complexes 7 and 9-13 (Fig. 4 and S97-S103†) were characterised by single-crystal X-ray crystallography. Relevant parameters are listed in Table S1. $\dagger$ All structures except $\mathbf{9}$ and $\mathbf{1 0}$ contained disordered $\mathrm{CH}_{2} \mathrm{Cl}_{2}$ or $\mathrm{CD}_{2} \mathrm{Cl}_{2}$ of crystallisation.

In meso complexes 7, 9 and 12, the molecule possesses a crystallographic inversion centre (located at the midpoint of the $\mathrm{N}-\mathrm{N}$ bond) relating the $\Lambda$ and $\Delta$ metal centres. The rac complexes 10, 11 and 13 all crystallise in centrosymmetric space groups, thus each molecule is chiral $(\Lambda \Lambda$ or $\Delta \Delta)$ but the crystal is racemic. Two solvent-free polymorphs of $\mathbf{1 0}$ formed concomitantly; in $\alpha-\mathbf{1 0}$ the molecule lies on a crystallographic twofold axis while in $\beta-\mathbf{1 0}$ (as in $\mathbf{1 1}$ and 13) it has no crystallographic symmetry. Each Ir atom has distorted octahedral coordination, involving one $\mathrm{N}$ and one $\mathrm{O}$ atom of the bridging hydrazide (OCNNCO) ligand, and two $\mathrm{C}^{\wedge} \mathrm{N}$ cyclometalating ligands. As usual, the $\mathrm{N}$ atoms of the latter occupy axial positions, trans to one another. ${ }^{6,21}$ As reported earlier, ${ }^{22}$ in meso complexes the hydrazide moiety is planar, while in rac isomers it is variously (by 7 to $24^{\circ}$ ) folded along the central $\mathrm{N}-\mathrm{N}$ bond into two planar OCNN chelating fragments. The chelated Ir atoms can be coplanar with, or displaced from, their planes, but this does not affect the bonding pattern significantly. Each aryl substituent (A) at the bridging ligand is oriented approximately perpendicular to the hydrazide plane (thus precluding $\pi$-conjugation) and is stacked face-to-face $(\pi-\pi)$ with a cyclometalating ligand, essentially with its phenyl ring (B) (Fig. 4, S98S101 and S103†). This will shorten the effective conjugation
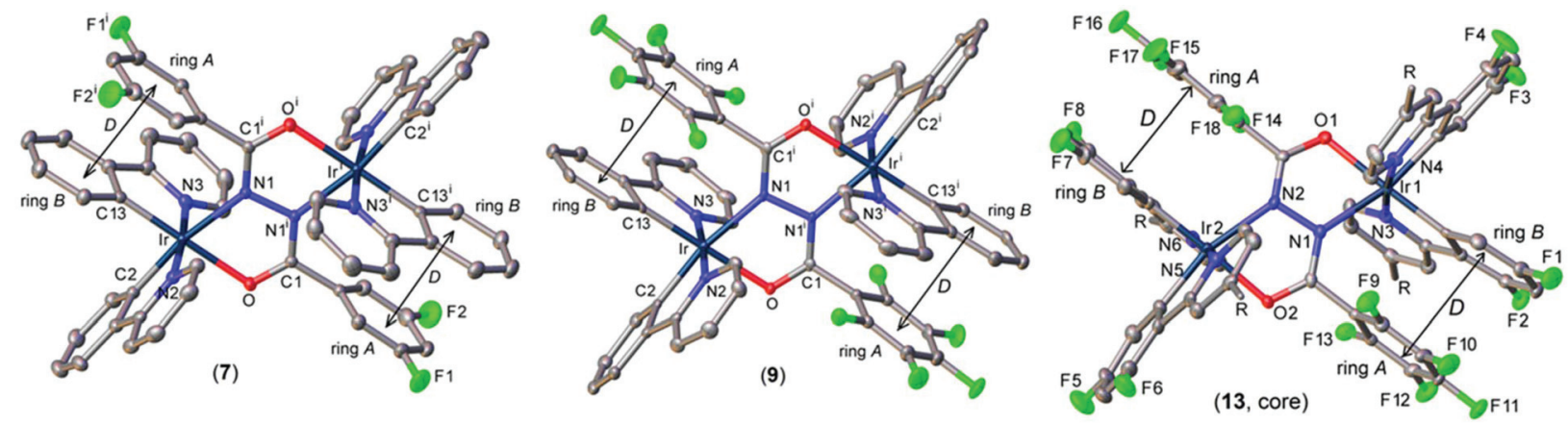

Fig. 4 X-ray molecular structures of meso 7, meso 9 and the core part of rac $13(\Delta \Delta)$ with the xylyl substituents (R) omitted. Thermal ellipsoids are drawn at $50 \%$ probability level. $\mathrm{H}$ atoms are omitted for clarity. Vector $D$ identifies intramolecular $\pi-\pi$ interactions, meso $7=3.32 \AA$, meso $9=3.24 \AA$, $\operatorname{rac} 13=3.27,3.19 \AA$ A. 
length of the bridge and is beneficial for shifting emission towards the blue (see below).

Generally, the stacking is closer and more parallel than in previously studied analogues with $t$-Bu and $\mathrm{CF}_{3}$-substituents. $^{21,22}$ To the best of our knowledge the systems studied here demonstrate the closest intramolecular $\pi-\pi$ stacking reported for cyclometallated iridium complexes. ${ }^{22,29-33}$ Comparison of the two polymorphs of $\mathbf{1 0}$ shows that different crystal packing has limited effect on the molecular conformation: in $\alpha-\mathbf{1 0}$ both rings $\mathrm{A}$ in a molecule are eclipsed with corresponding rings $\mathrm{B}$, in $\boldsymbol{\beta}-\mathbf{1 0}$ one pair is nearly eclipsed and the other shows a quasi-graphitic overlap, ring A shifting towards the pyridyl ring of the $\mathrm{C}^{\wedge} \mathrm{N}$ ligand. Interestingly, molecule 12, which lacks intramolecular stacking, is much less rigid - note the different conformations of two crystallographically non-equivalent molecules in the crystal (Fig. S102†).

\section{Computational study}

The optimised ground state $\mathrm{S}_{0}$ geometries for the complexes were calculated at the B3LYP/LANL2DZ:3-21G* level with the LANL2DZ pseudopotential for the iridium atoms and the 3$21 \mathrm{G}^{*}$ basis set for other atoms. This model chemistry was selected on the basis of previous computational studies, ${ }^{50,53}$ and ensures that these calculations are directly comparable with those reported for other diiridium complexes (such as complex 1). ${ }^{21,22}$ For the complexes 13-15 the methylene cyclohexylether groups were substituted for methoxy groups to shorten calculation times. The geometries of the central hydrazide fragments are in good agreement with the XRD results discussed above.

Molecular orbital calculations provided insight into the localisation of the frontier molecular orbitals (FMOs). Reasonable agreement is observed between diastereomers for all complexes. The LUMOs are localised on the cyclometalating ligands, particularly the pyridyl moieties. ${ }^{21,22}$ However, the localisation of the highest occupied molecular orbitals (HOMOs) varies more significantly between complexes: in some cases the HOMO contribution from the bridge centre is high ( $\geq 30 \%$ ) (complexes 7, 10, 13 and 15) whereas in other cases the bridging ligands display ancillary character (complexes 8, 9, 11, 12 and 14). In this study, if the average HOMO contribution from the bridge centre for both diastereomers is $<15 \%$, the bridge is considered ancillary. This is summarised in Table S2. $\dagger$ FMO plots for complexes 7, 9, 12 and 13 are given in Fig. 5 as representative examples. FMO plots for the other complexes are shown in Fig. S126-S143. $\dagger$

For complex 7 the HOMO has significant contributions from the Ir centres, the central component of the hydrazide bridge and the cyclometalating phenyl moieties, as in complex 1. ${ }^{21,22}$ Further fluorination of the bridging aryl rings decreases the bridge HOMO contributions for complexes 8 (octafluoro) and 9 (decafluoro), so their HOMOs are primarily localised on the Ir centres and the cyclometalating phenyl groups, with their bridges expected to behave as ancillary ligands. As complex 10 also features methoxy groups on the bridging unit, the effect of the electron withdrawing fluorine atoms is some-

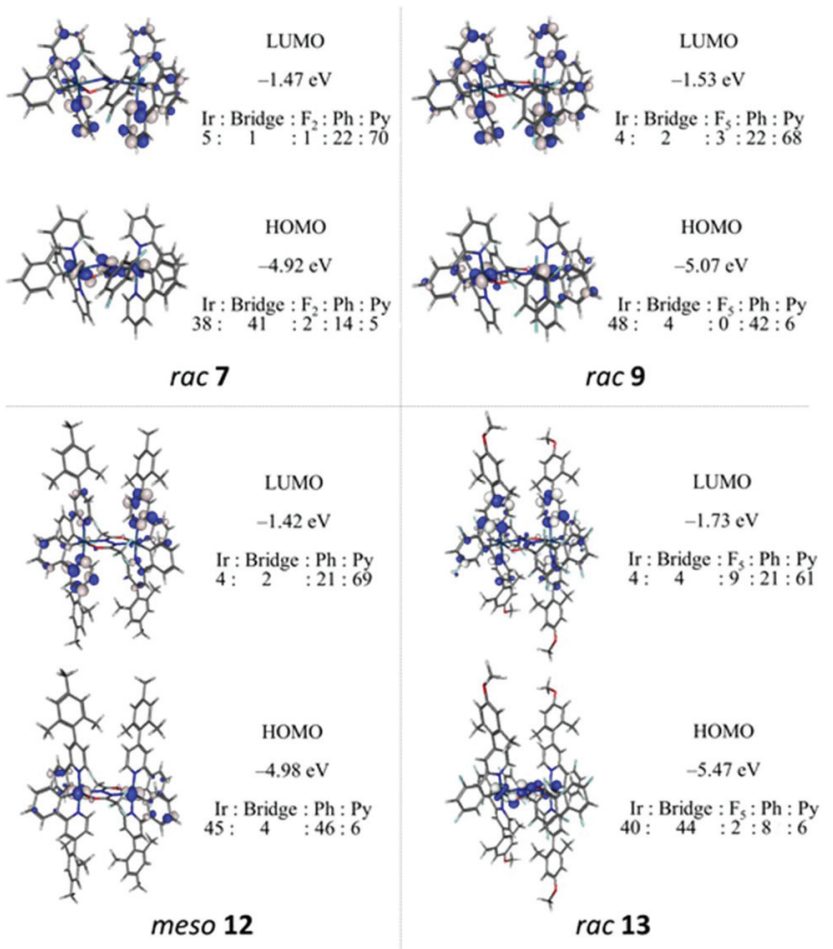

Fig. 5 Molecular orbital compositions for complexes rac 7, rac 9, meso 12 and rac 13 . The stated ratios represent the atom/group contributions in percentages. Bridge = central OCNNCO fragment.

what negated and the bridge still features notable HOMO localisation (32\% average). Calculations predict very similar HOMO contributions for complexes 9 and 11, indicating that the mesityl groups have a negligible electronic effect, as expected. ${ }^{47,48}$ Lowering the $\pi$ orbital energy of the cyclometalating ligands of complexes 13 and 15 through fluorination strongly shifts their HOMOs onto the bridging ligands so that the cyclometalating phenyl moieties have very low HOMO contributions (average of both diastereomers $<15 \%$ for both complexes). There is negligible frontier orbital (HOMO or LUMO) contribution from the bridge aryl rings for all complexes featuring diarylhydrazide bridges, even upon perfluorination.

For complexes $\mathbf{1 2}$ and $\mathbf{1 4}$ the bridging ligands are ancillary with negligible HOMO contributions (average of both diastereomers $=4 \%$ for both complexes), regardless of cyclometalating ligand fluorination. This is indicative of the shorter conjugation length of the bis(trifluoromethyl) bridge 18 compared to the diarylhydrazide bridges studied here.

\section{Electrochemistry}

Complexes 7-15 (Fig. 2) were studied by cyclic voltammetry (CV) to obtain their oxidation and reduction potentials. The data are listed in Table 1 and voltammograms are shown in Fig. S104-S125.† All complexes display two electrochemically reversible oxidation waves. These represent sequential oxidation of the iridium centres $\left(\mathrm{Ir}^{3+} / \mathrm{Ir}^{4+}\right.$ redox couples), which are electronically coupled via the conjugated bridging units 
Table 1 Electrochemical data for complexes 7-15

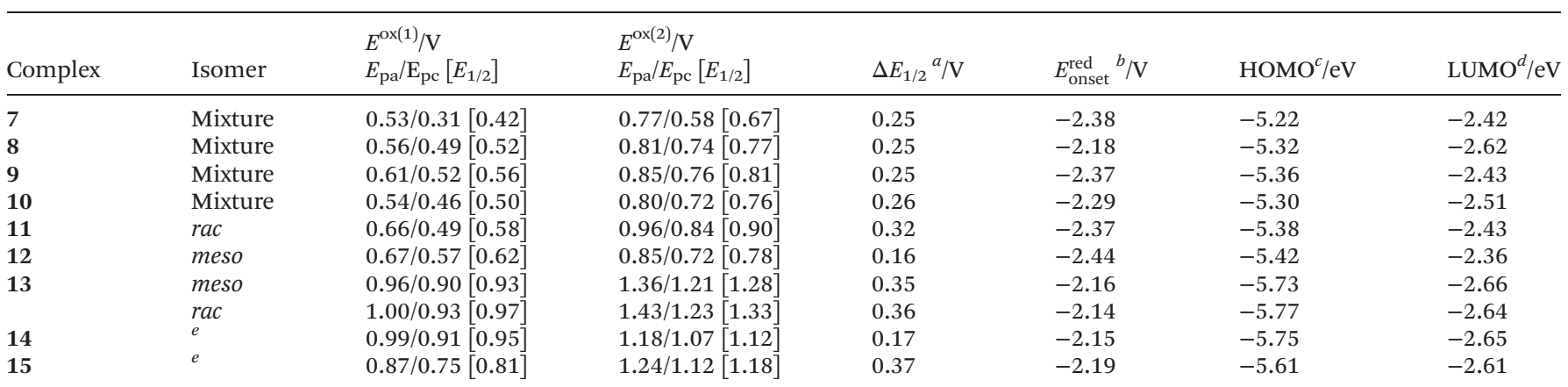

${ }^{a}$ Peak splitting between $E^{\mathrm{ox}(1)}$ and $E^{\mathrm{ox}(2)} \cdot{ }^{b}$ All reductions are electrochemically irreversible. ${ }^{c}$ HOMO levels calculated from CV potentials by HOMO $=-4.8+\left(-E_{1 / 2}^{\text {ox }(1)}\right)$, using ferrocene as the standard. ${ }^{d}$ LUMO levels calculated from CV potentials by LUMO $=-4.8+\left(-E_{\text {onset }}^{\text {red }}\right)$, using ferrocene as the standard. ${ }^{e}$ Complexes $\mathbf{1 4}$ and $\mathbf{1 5}$ were isolated as single diastereomers; their absolute configurations are unknown.

and so are electrochemically inequivalent. For complexes $\mathbf{1 1}$ and $\mathbf{1 5}$ as representative examples, both oxidation processes were shown to be chemically reversible over 10 cycles (Fig. S114 and S115†).

Complex 7, which features 4 fluorine atoms on the bridging unit, displays the lowest first oxidation potential $\left(E^{\mathrm{ox}(1)}\right)$. As expected, increasing to 8 (complex 8) and 10 fluorine atoms (complex 9) leads to successively higher oxidation potentials. Due to the addition of electron-rich methoxy groups to the octafluoro bridging unit, the oxidation potential of complex $\mathbf{1 0}$ is slightly decreased by $0.02 \mathrm{~V}$ compared to complex 9 . A relatively small variation in oxidation potentials $(0.04 \mathrm{~V})$ across the series 7-10 supports DFT predictions that the bridges in $\mathbf{8}$ and 9 behave as ancillary ligands. Complexes $\mathbf{7 - 1 0}$, which vary only in the extent of bridge fluorination, all feature very similar peak splittings $\left(\Delta E_{1 / 2} c a .0 .25 \mathrm{~V}\right)$, indicating similar electronic coupling between the Ir centres for this series.

Functionalising the ppy ligands of complex 11 with mesityl groups does not significantly influence $E^{\mathrm{ox}(1)}$ (an increase of only $0.02 \mathrm{~V}$ is observed compared to complex 9), indicating that they have minimal electronic effect. ${ }^{47,48}$ However, it is interesting that the second oxidation potential $\left(E^{\mathrm{ox}(2)}\right)$ of 11 is shifted to a significantly higher potential compared to complex $9(0.90 \mathrm{~V} v s$. $0.81 \mathrm{~V})$ leading to a larger $\Delta E_{1 / 2}$ value of $0.32 \mathrm{~V}$ for 11 compared to $0.25 \mathrm{~V}$ for $\mathbf{9}$. A tentative explanation is that the mesityl groups, could sterically interact over the bridging unit (Fig. S101†). This would lower the molecular flexibility and could hinder structural rearrangement to the dication, thereby increasing $E^{\mathrm{ox}(2)}$ of $\mathbf{1 1}$ compared to the more flexible complex 9.

The oxidation potential of $\mathbf{1 2}$ is higher than that of $\mathbf{1 1}$ by $0.04 \mathrm{~V}$, suggesting that the bis(trifluoromethyl)-functionalised bridge (18) is more strongly electron withdrawing than the bis (pentafluorophenyl) bridge $(\mathbf{1 7 c}) .{ }^{46}$ The $\Delta E_{1 / 2}$ value obtained for $12(0.16 \mathrm{~V})$ is also half of that observed for 11, implying weak communication between the two iridium centres. This is in line with the ancillary nature of the bridge and in agreement with DFT (Table S2 $\dagger$ ). The addition of fluorinated cyclometalating ligands to complexes meso 13 and rac 13 further shifts their oxidation potentials to more positive values, as expected from DFT, which predicts high HOMO contributions from the cyclometalating phenyl rings of complex 11 (Table $\mathrm{S} 2 \dagger$ ). The $\Delta E_{1 / 2}$ values for meso 13 and rac 13 are also greater than for complex 11 (by 0.03/0.04 V) which may be due to the reduced ancillary character of the bis(pentafluorophenyl) bridge in these complexes, also in line with DFT predictions.

Complex 14 has an oxidation potential almost identical to meso 13 and rac 13, indicating very similar HOMO energies. Analogous to the relationship between complexes 11 and 12, complex 14 displays a much lower $\Delta E_{1 / 2}$ value than either diastereomer of complex 13, which suggests a higher ancillary character of the bis(trifluoromethyl) bridge (and so weaker Ir...Ir communication), as inferred by DFT.

The first oxidation potential of $\mathbf{1 5}$ is cathodically shifted compared to complexes 13 (by $c a$. $0.1 \mathrm{~V}$ ). This is due to the absence of the xylyl spacer which electronically decouples the electron donating methylenecyclohexylether group from the ppy ligands. Complex 15 also has the largest $\Delta E_{1 / 2}$ value $(0.37 \mathrm{~V})$, in agreement with DFT which predicts the bridging unit to be the least ancillary of the series (Table S2 $\dagger$ ).

The reduction potentials for 7-15 were also estimated by CV. The data for the reduction scans are included in Table 1 and the voltammograms are shown in Fig. S116-125. $\dagger$ All complexes display irreversible reductions. This adds significant error to their accurate determination, complicating the detailed analysis of any trends. A similar situation has been previously encountered in the study of monoiridium complexes by Baranoff and Nazeeruddin et al. ${ }^{54}$ Nevertheless, the reduction onsets for the complexes 7-15 are in the range of -2.1 to $-2.4 \mathrm{~V} v s$. $\mathrm{FcH} / \mathrm{FcH}^{+}$, which is a reasonable fit with their emission energies (discussed below) and are similar to those reported for ppy-based monoiridium complexes. ${ }^{55}$ Generally, functionalisation of the cyclometallating ligands of 13-15 with electron-withdrawing fluorine atoms decreases their reduction potentials compared to those of complexes 7-12 as expected. ${ }^{55}$ The reduction potential for $\mathbf{1 5}$ is marginally greater than for 13 and $14(-2.19 \mathrm{~V} v s$. $-2.14 /-2.16 \mathrm{~V}$ and 
$-2.15 \mathrm{~V})$, which is expected from the DFT data upon direct functionalisation of the LUMO-bearing pyridyl moieties with electron-donating methylenecyclohexyl ether groups.

\section{Photophysical data}

The emission spectra for the complexes are shown in Fig. 6-9 and Fig. S155-S157† and the key photophysical data are given in Table 2. Absorption data are presented in Fig. S154 and Table S3. $\uparrow$ Complex 7 is nonemissive in DCM solution at room temperature, while being highly emissive (PLQY $=61 \pm 10 \%$ ) when doped into a rigid poly(methyl methacrylate) (PMMA) matrix. This is consistent with the data for complex $\mathbf{1},{ }^{22}$ for which the flexible central bridging unit (that DFT predicts to have significant HOMO character) can provide a pathway for non-radiative quenching of the excited state in solution, which can be inhibited by doping the complex into a rigid host matrix.

Complexes 8-10 have significantly different photophysical properties than 7 , in that they are highly emissive in solution and in PMMA, with very similar PLQY values in both media. This is consistent with rigidification of 8-10 by intramolecular

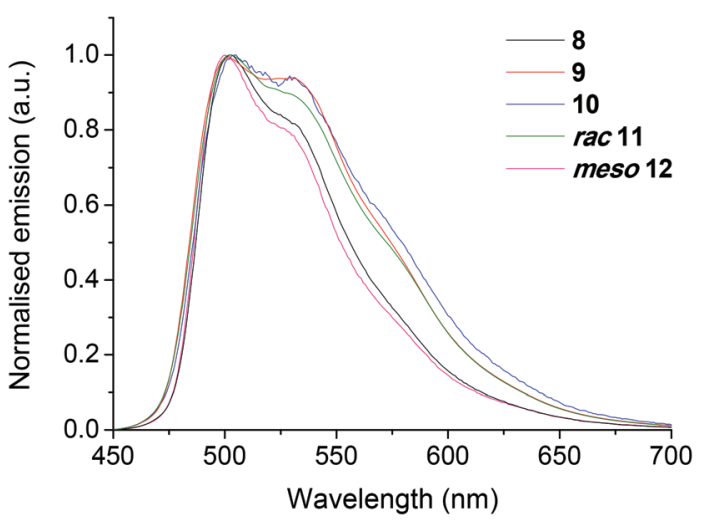

Fig. 6 Normalised emission spectra of complexes 8-12 in degassed DCM solutions at room temperature ( $\lambda_{\text {exc }} 355 \mathrm{~nm}$ ).

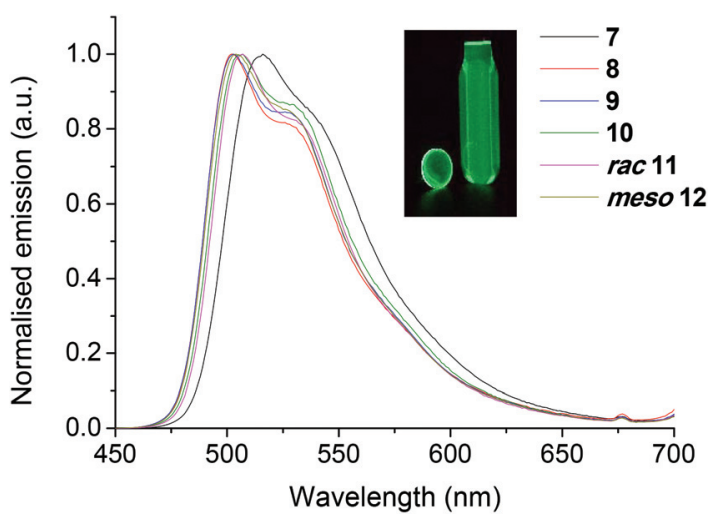

Fig. 7 Normalised emission spectra of complexes 7-12 doped into PMMA at $1 \mathrm{wt} \%$ at room temperature ( $\left.\lambda_{\text {exc }} 355 \mathrm{~nm}\right)$. Inset: photograph of emission from a doped PMMA film (left) and degassed DCM solution (right) of rac 11 under irradiation from a $365 \mathrm{~nm}$ UV lamp.

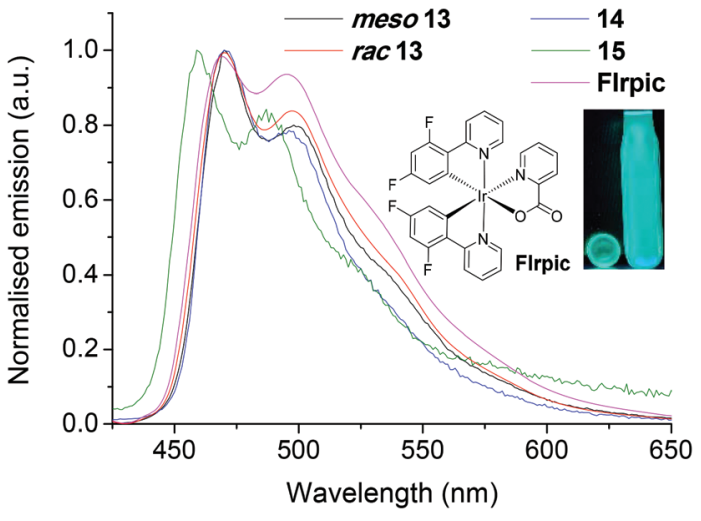

Fig. 8 Normalised emission spectra of complexes 13-15 and Flrpic in degassed DCM solutions at room temperature $\left(\lambda_{\text {exc }} 355 \mathrm{~nm}\right)$. The emission spectrum of 15 is poorly resolved due to a low solution PLQY. Inset: (left) chemical structure of Flrpic. (Right) photograph of emission from a doped PMMA film and degassed DCM solution of rac 13 under irradiation from a $365 \mathrm{~nm}$ UV lamp.

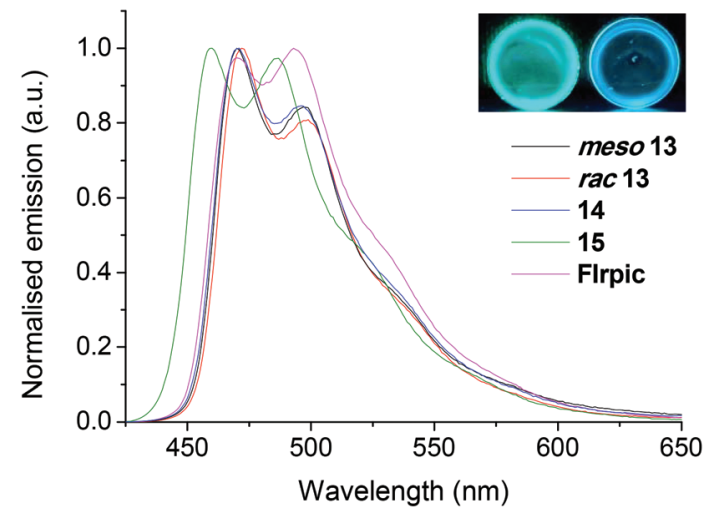

Fig. 9 Normalised emission spectra of complexes 13-15 and Flrpic doped into PMMA at 1 wt\% at room temperature ( $\lambda_{\text {exc }} 355 \mathrm{~nm}$ ). Inset: photograph of the emission from doped PMMA films of rac 13 (left) and 15 (right) under irradiation from a 365 nm UV lamp.

$\pi-\pi$ stacking, which restricts rotation of the bridge aryl rings. This is observed in the solution ${ }^{19} \mathrm{~F}$ NMR spectra of 8-10 (Fig. 3, S5, S9, S15 and S18 $\dagger$ ) and removes the requirement to impede bridge flexibility by using a rigid matrix such as PMMA.

Another possible explanation is that for complexes with an ancillary bridging unit (Table $\mathrm{S} 2 \dagger$ ) such as $\mathbf{8}$ and $\mathbf{9}$, motion of the bridge does not provide as efficient a non-radiative pathway to the ground state in solution. However, as complex 10 features a non-ancillary bridge with notable HOMO character (Table S2 $\dagger$ ) while still exhibiting a high solution PLQY (78 $\pm 5 \%$ ), it is evident that intramolecular $\pi-\pi$ stacking is the main reason for high solution PLQYs in highly fluorinated diarylhydrazide-bridged diiridium complexes.

The emission spectra of $\mathbf{8 - 1 0}$ are blue shifted compared to 7 (by ca. $10 \mathrm{~nm}$ in PMMA) (Fig. 7). This is a result of HOMO stabilisation through further fluorination of the bridging units 


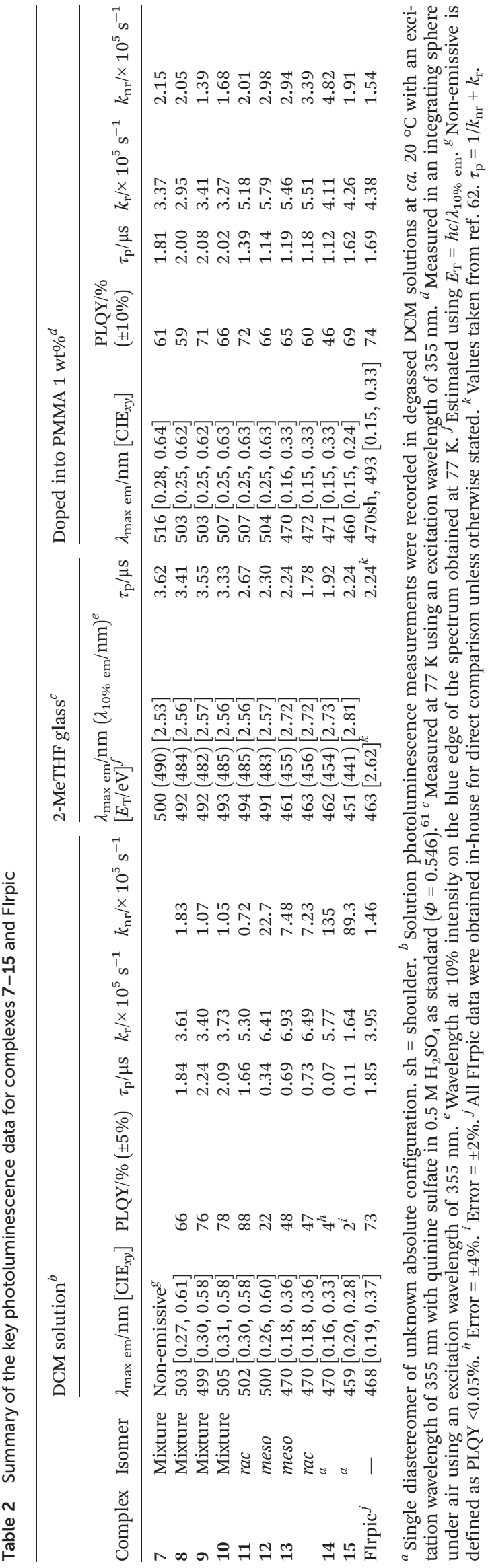

(in agreement with electrochemical data - Table 1). Complexes 8-10 exhibit near identical Commission Internationale de $\mathrm{L}^{\prime}$ Éclairage $\left(\mathrm{CIE}_{x y}\right)$ colour coordinates in PMMA of $(0.25,0.62 /$ $0.63)$ in the green region of the spectrum. The triplet energies $\left(\mathrm{E}_{T}\right)$ for 8-10 (obtained from emission spectra recorded in 2-MeTHF at $77 \mathrm{~K}$, Fig. S156†) are also nearly identical $(2.56-2.57 \mathrm{eV})$. These data provide additional experimental support for the DFT prediction that the bridges in $\mathbf{8}$ and $\mathbf{9}$ behave as ancillary ligands.

The mesityl groups in rac $\mathbf{1 1}$ result in a significant increase in the radiative rate constant $\left(k_{\mathrm{r}}\right)$ compared to complex 9 in DCM solution (5.30 vs. $\left.3.40 \times 10^{5} \mathrm{~s}^{-1}\right)$ and in PMMA (5.18 vs. $\left.4.41 \times 10^{5} \mathrm{~s}^{-1}\right)$. This leads to a small increase in solution PLQY ( $88 \pm 5 \%$ for rac $\mathbf{1 1} v s .76 \pm 5 \%$ for complex 9 ), whereas the PLQYs in PMMA for $\mathbf{9}$ and rac $\mathbf{1 1}$ are very similar (71 $\pm 10 \%$ and $72 \pm 10 \%$, respectively). The incorporation of mesityl groups is known to increase PLQYs and $k_{\mathrm{r}}$ values in monoiridium systems. ${ }^{47,48}$ As mesityl groups have a negligible electronic effect, the $\mathrm{CIE}_{x y}$ coordinates (in both DCM an PMMA) and $E_{\mathrm{T}}$ values for $\mathbf{9}$ and rac $\mathbf{1 1}$ are nearly identical. ${ }^{47,48}$

Complex meso $\mathbf{1 2}$ is moderately emissive in DCM solution $(\mathrm{PLQY}=22 \pm 5 \%)$ and is highly emissive in PMMA (PLQY $=$ $66 \pm 10 \%$ ). This is due to an order of magnitude decrease in $k_{\mathrm{nr}}$ upon doping the complex into PMMA (Table 2), which can be attributed to higher molecular flexibility inferred from the XRD data (discussed above, Fig. S102†). Although meso 12 is not rigidified by intramolecular $\pi-\pi$ interactions, it is still emissive in solution, albeit to a lesser extent than rac 11. This may be related to the ancillary nature of the bridging ligand (predicted by DFT), which may reduce the efficiency of nonradiative quenching through bridge motion, as mentioned above.

Other than their solution PLQY values and the presence/ absence of intramolecular $\pi-\pi$ interactions, complexes rac $\mathbf{1 1}$ and meso 12 display similar theoretical (Table S2 $\dagger$ ), electrochemical (Table 1) and photophysical (Table 2) properties. A direct comparison therefore serves as good evidence that intramolecular $\pi-\pi$ interactions contribute significantly to the high solution PLQYs of the diarylhydrazide-bridged complexes.

Incorporation of the fluorinated cyclometalating ligand 21 into the diastereomers meso $\mathbf{1 3}$ and rac $\mathbf{1 3}$ shifts their emission energies into the sky-blue region (Fig. 8 and 9). In DCM both meso 13 and rac 13 have PLQYs of $47 / 48 \pm 5 \%$ with $\mathrm{CIE}_{x y}$ coordinates $(0.18,0.36)$ marginally lower than the archetypal skyblue emitter FIrpic (Fig. 8) $)^{38,56}(0.19,0.37)$, even though their $\lambda_{\max }$ values are red shifted compared to FIrpic by $2 \mathrm{~nm}$. This is related to their narrower full width at half maximum (FWHM) values because of diminished $\mathrm{v}_{0,1}$ vibronic shoulders: FWHM FIrpic $=82 \mathrm{~nm}$, meso $\mathbf{1 3}=63 \mathrm{~nm}, \operatorname{rac} \mathbf{1 3}=69 \mathrm{~nm}$. This is again consistent with higher molecular rigidity, due to the intramolecular $\pi-\pi$ interactions (observed in the ${ }^{19} \mathrm{~F}$ NMR spectra of meso 13 and rac 13 - Fig. S42 and S51†).

Molecular rigidity also influences the Huang-Rhys factor $\left(S_{\mathrm{M}}\right)$, which is proportional to the degree of structural distortion which occurs in the excited state of a molecule relative to the ground state. ${ }^{57} S_{\mathrm{M}}$ values were estimated for FIrpic, meso 
13 and rac 13 from the relative heights of the $\mathrm{v}_{0,0}$ and $\mathrm{v}_{0,1}$ peaks in their $77 \mathrm{~K}$ emission spectra (Fig. S157, $\dagger$ FIrpic spectrum obtained from ref. 56). ${ }^{57,58}$ The following values were obtained: FIrpic $=0.7$, meso $13=0.4$, rac $13=0.5$ (1 s.f.). These values indicate a lower intensity vibronic progression for the rigid diiridium complexes compared to FIrpic, which is vital for obtaining high colour purity.

Similarly, favourable photophysical properties are also observed for meso 13 and rac 13 when doped into PMMA: high PLQYs of $60 / 65 \pm 10 \%$ (FIrpic $74 \pm 10 \%$ ) and comparatively narrow FWHM values of 55/56 nm (FIrpic 67 nm) (Fig. 9).

These comparatively narrow emission spectra are significant as the complexes are predicted to feature non-ancillary bridging ligands (see the DFT discussed above), which will likely lead to excited states with noteworthy interligand charge transfer (ILCT) character. ILCT character leads to broader, less structured emission due to more diffusely localised excited states. ${ }^{58-60}$ It is expected that the rigidifying effect of the intramolecular $\pi-\pi$ interactions counteracts this, promoting sharper emission bands. These data indicate that diiridium complexes show promise as a platform for developing blue phosphors with good colour purity.

meso 13 and rac 13 feature higher $k_{\mathrm{r}}$ values than FIrpic (by $\sim 20-40 \%$ ) under directly comparable conditions in both DCM solution and PMMA. This may be related to the strong Ir...Ir coupling observed in the electrochemistry (Table 1), and results in notably shorter $\tau_{\mathrm{p}}$ values in PMMA of 1.18/1.19 $\mu \mathrm{s}$ (vs. $1.69 \mu$ s for FIrpic).

Enhanced radiative rate constants compared to monoiridium analogues have been reported for green to red diiridium complexes, which may be due to augmented spin-orbit coupling. ${ }^{23,24,26,50,63}$ Blue phosphors tend to possess excited states with more LC character than green emitting complexes, ${ }^{64-66}$ which is an indication of poorer LC/MLCT state mixing (lower MLCT character) and can lead to inherently lower $k_{\mathrm{r}}$ values and so longer $\tau_{\mathrm{p}}$. The observations presented here indicate that diiridium complexes are promising systems for developing blue phosphors with higher $k_{\mathrm{r}}$ values and therefore shorter $\tau_{\mathrm{p}}$ which is a highly sought-after property. ${ }^{67}$

In a similar manner to the relationship between rac 11 and meso 12, complex 14 is an analogue of $\mathbf{1 3}$ which cannot exhibit intramolecular $\pi-\pi$ interactions between the cyclometalating and bridging ligands. As a result, 14 displays a low solution PLQY of $4 \pm 4 \%$. In PMMA the PLQY of 14 increases to $46 \pm$ $10 \%$, which is ascribed to a restriction of intramolecular motion, evident from the substantial decrease in $k_{\mathrm{nr}}$ (Table 2). The PLQY of 14 in PMMA is, however, significantly lower than those for either diastereomer of $13(60 / 65 \pm 10 \%)$. This is due to: (1) a substantially higher $k_{\mathrm{nr}}$ value, which crucially indicates that intramolecular $\pi-\pi$ interactions are also beneficial for obtaining high solid state PLQY values in diiridium complexes, and (2) a lower $k_{\mathrm{r}}$ value (Table 2), which may be related to the smaller Ir...Ir coupling in $\mathbf{1 4}$ observed in the electrochemistry (Table 1).

Despite the lack of rigidifying intramolecular $\pi-\pi$ interactions, 14 exhibits sharp emission similar to 13 (FWHM in
PMMA $=57 \mathrm{~nm}$ ) (Fig. 9). This is consistent with the ancillary nature of the bis(trifluoromethyl) bridge 18, which is expected to limit the ILCT character of the excited state. The estimated $S_{\mathrm{M}}$ value for 14 is 0.6 (1 s.f.): larger than for either diastereomer of 13, but still smaller than for FIrpic. These data indicate that designing diiridium complexes with highly ancillary bridges could be a way to obtain sharp emission from such systems.

The emission from complex $\mathbf{1 5}$ is shifted deeper into the blue than for $\mathbf{1 3}$ or $\mathbf{1 4}$. This is attributed to the LUMO-destabilising methylenecyclohexylether groups. As well as being tentatively observed in the reduction potentials above (Table 1), this can also be concluded from the more reliable oxidation potential data which indicate that the HOMO of $\mathbf{1 5}$ is shallower than for 13 or 14. When doped into PMMA, 15 displays a high PLQY of $69 \pm 10 \%$. This is comparable to the value obtained for FIrpic under the same experimental conditions, while the colour is notably superior: 15 emits at a $\lambda_{\max }$ of $460 \mathrm{~nm}$, pushing the $\mathrm{CIE}_{x y}$ coordinates to a total value below $0.4(0.15$, 0.24). Complex 15 also displays a $\tau_{\mathrm{p}}$ of $1.62 \mu \mathrm{s}$ in PMMA, which is short in a doped film for an Ir complex with total $\mathrm{CIE}_{x y}<$ $0.4 / \lambda_{\max } \leq 460 \mathrm{~nm}$ and a high PLQY. ${ }^{47,68-71}$ This can be attributed to the high $k_{\mathrm{r}}$, which is likely related to the dinuclear nature of the complex as mentioned above.

Despite the presence of rigidifying intramolecular $\pi-\pi$ interactions (observed in the ${ }^{19}$ F NMR spectrum - Fig. S68 $\dagger$ ), the PLQY for 15 in DCM solution is low $(2 \pm 2 \%)$. This fits a trend of decreasing solution PLQY with increasing emission energy in the complexes rac $11\left(\lambda_{\max }=502 \mathrm{~nm}\right.$, PLQY $\left.=88 \pm 5 \%\right), 13$ $\left(\lambda_{\max }=470 \mathrm{~nm}, \mathrm{PLQY}=47 / 48 \pm 5 \%\right)$ and $15\left(\lambda_{\max }=459 \mathrm{~nm}\right.$, PLQY $=2 \pm 2 \%$ ) due to incremental order of magnitude increases in their $k_{\mathrm{nr}}$ values $\left(0.72,7.23 / 7.48\right.$ and $89.3 \times 10^{5}$ $\left.\mathrm{s}^{-1}\right)$. In contrast, all three complexes exhibit high PLQYs $(>60 \%)$ and similar $k_{\mathrm{nr}}$ values (1.91-3.39 $\times 10^{5} \mathrm{~s}^{-1}$ ) when doped into PMMA. Therefore, it appears that as the excited state energy increases, the rigidifying effect of the intramolecular $\pi-\pi$ interactions is overcome and their capability to promote emission in solution is reduced.

Emission in the sky-blue region from diiridium complexes with conjugated bridging ligands is unprecedented. It has been accomplished by the synergistic choice of bridging and cyclometalating ligands. The key role of the bridge is clear as there are reports of diiridium complexes bearing dfppy-type peripheral ligands for which sky-blue emission was not achieved. 8,16,72-74 Although diiridium systems have shown promise as high performing phosphors in the lower energy range (from red through to green), ${ }^{21-24,26,27,50,75}$ to the best of our knowledge no complex displaying $\lambda_{\max }$ (PL) below $c a$. $490 \mathrm{~nm}$ at room temperature has been reported thus far. ${ }^{22}$ Mazzanti and co-workers reported a fluorinated diiridium complex with a vibronic sideband at $477 \mathrm{~nm}$, but the $\lambda_{\max }$ is ca. $510 \mathrm{~nm}$ and the emission extends to $800 \mathrm{~nm} .{ }^{16}$ The results presented here considerably extend the diiridium complex literature, and indicate that if the complexes are correctly designed, their colour versatility is potentially comparable to monoiridium systems. 


\section{Conclusions}

We have developed new concepts in the chemistry of diiridium complexes with the synthesis, structural and optoelectronic characterisation of a series of highly fluorinated hydrazidebridged complexes.

Complexes 7-12 represent an ideal platform for investigating intramolecular $\pi-\pi$ interactions between aryl and perfluoroaryl rings in organometallic systems, both in the solid state (by XRD) and in solution (by ${ }^{19} \mathrm{~F}$ NMR spectroscopy). These interactions are shown to be an innovative way to rigidify diiridium complexes, leading to significant and advantageous effects on their photophysical properties. Electrochemical and computational studies have further extended the understanding of these systems. This knowledge has been applied to the rational design and synthesis of the first reported sky-blue emitting diiridium complexes 13-15. Their favourable photophysical properties are a consequence of both the dinuclear nature of the complexes and the beneficial intramolecular $\pi-\pi$ interactions. They possess high PLQYs, $\lambda_{\max }$ as low as $460 \mathrm{~nm}\left(\mathrm{CIE}_{x+y}<0.4\right)$, high $k_{\mathrm{r}}$, relatively short $\tau_{\mathrm{p}}$, and in some cases, notably sharp emission. The results presented here greatly extend the versatility of luminescent diiridium complexes by shifting phosphorescence into the sky-blue region of the visible spectrum with the aid of tailored non-covalent interactions. It is now a challenge to design and implement further structural modifications that could shift the emission of diiridium complexes deeper in the blue region.

\section{Conflicts of interest}

There are no conflicts to declare.

\section{Acknowledgements}

Dr Alan Kenwright and Dr Juan Aguilar-Malavia are acknowledged for their help in devising, running and interpreting 2D NMR experiments. Prof. Graham Sandford is acknowledged for helpful ${ }^{19} \mathrm{~F}$ NMR discussion. We thank EPSRC grant EP/ L02621X/1 for funding.

\section{Notes and references}

1 Z. Q. Chen, Z. Q. Bian and C. H. Huang, Adv. Mater., 2010, 22, 1534-1539.

2 M. S. Lowry and S. Bernhard, Chem. - Eur. J., 2006, 12, 7970-7977.

3 K. K.-W. Lo, K. H.-K. Tsang, K.-S. Sze, C.-K. Chung, T. K.-M. Lee, K. Y. Zhang, W.-K. Hui, C.-K. Li, J. S.-Y. Lau, D. C.-M. Ng and N. Zhu, Coord. Chem. Rev., 2007, 251, 2292-2310.
4 R. Gao, D. G. Ho, B. Hernandez, M. Selke, D. Murphy, P. I. Djurovich and M. E. Thompson, J. Am. Chem. Soc., 2002, 124, 14828-14829.

5 X. Yang, G. Zhou and W.-Y. Wong, Chem. Soc. Rev., 2015, 44, 8484-8575.

6 C. Ulbricht, B. Beyer, C. Friebe, A. Winter and U. S. Schubert, Adv. Mater., 2009, 21, 4418-4441.

7 Y. Chi and P.-T. Chou, Chem. Soc. Rev., 2010, 39, 638-655.

8 X. Yuan, S. Zhang and Y. Ding, Inorg. Chem. Commun., 2012, 17, 26-29.

9 L. Donato, C. E. McCusker, F. N. Castellano and E. ZysmanColman, Inorg. Chem., 2013, 52, 8495-8504.

10 A. Tsuboyama, T. Takiguchi, S. Okada, M. Osawa, M. Hoshino and K. Ueno, Dalton Trans., 2004, 1115-1116.

11 E. A. Plummer, W. Hofstraat and L. De Cola, Dalton Trans., 2003, 2080-2084.

12 A. Auffrant, A. Barbieri, F. Barigelletti, J. Lacour, P. Mobian, J.-P. Collin, J.-P. Sauvage and B. Ventura, Inorg. Chem., 2007, 46, 6911-6919.

13 V. L. Whittle and J. A. G. Williams, Inorg. Chem., 2008, 47, 6596-6607.

14 W.-J. Xu, S.-J. Liu, X. Zhao, N. Zhao, Z.-Q. Liu, H. Xu, H. Liang, Q. Zhao, X.-Q. Yu and W. Huang, Chem. - Eur. J., 2013, 19, 621-629.

15 V. Chandrasekhar, B. Mahanti, P. Bandipalli and K. Bhanuprakash, Inorg. Chem., 2012, 51, 10536-10547.

16 E. S. Andreiadis, D. Imbert, J. Pécaut, A. Calborean, I. Ciofini, C. Adamo, R. Demadrille and M. Mazzanti, Inorg. Chem., 2011, 50, 8197-8206.

17 A. G. Tennyson, E. L. Rosen, M. S. Collins, V. M. Lynch and C. W. Bielawski, Inorg. Chem., 2009, 48, 6924-6933.

18 T. Hajra, A. J. K. Bera and V. Chandrasekhar, Aust. J. Chem., 2011, 64, 561-566.

19 A. M. Prokhorov, A. Santoro, J. A. G. Williams and D. W. Bruce, Angew. Chem., Int. Ed., 2012, 51, 95-98.

20 M. Graf, R. Czerwieniec and K. Sünkel, Z. Anorg. Allg. Chem., 2013, 639, 1090-1094.

21 Y. Zheng, A. S. Batsanov, M. A. Fox, H. A. Al-Attar, K. Abdullah, V. Jankus, M. R. Bryce and A. P. Monkman, Angew. Chem., Int. Ed., 2014, 53, 11616-11619.

22 D. G. Congrave, Y.-t. Hsu, A. S. Batsanov, A. Beeby and M. R. Bryce, Organometallics, 2017, 36, 981-993.

23 G. Li, Y. Wu, G. Shan, W. Che, D. Zhu, B. Song, L. Yan, Z. Su and M. R. Bryce, Chem. Commun., 2014, 50, 69776980.

24 P.-H. Lanoë, C. M. Tong, R. W. Harrington, M. R. Probert, W. Clegg, J. A. G. Williams and V. N. Kozhevnikov, Chem. Commun., 2014, 50, 6831-6834.

25 V. Chandrasekhar, T. Hajra, J. K. Bera, S. M. W. Rahaman, N. Satumtira, O. Elbjeirami and M. A. Omary, Inorg. Chem., 2012, 51, 1319-1329.

26 R. E. Daniels, S. Culham, M. Hunter, M. C. Durrant, M. R. Probert, W. Clegg, J. A. G. Williams and V. N. Kozhevnikov, Dalton Trans., 2016, 45, 6949-6962.

27 X. Yang, Z. Feng, J. Zhao, J.-S. Dang, B. Liu, K. Zhang and G. Zhou, ACS Appl. Mater. Interfaces, 2016, 8, 33874-33887. 
28 Z. Hao, H. Jiang, Y. Liu, Y. Zhang, J. Yu, Y. Wang, H. Tan, S. Su and W. Zhu, Tetrahedron, 2016, 72, 8542-8549. Although emission of a similar colour to FIrpic is reported, the two Ir centres are non-conjugated.

29 A. M. Bünzli, E. C. Constable, C. E. Housecroft, A. Prescimone, J. A. Zampese, G. Longo, L. Gil-Escrig, A. Pertegás, E. Ortí and H. J. Bolink, Chem. Sci., 2015, 6, 2843-2852.

30 E. C. Constable, C. E. Housecroft, P. Kopecky, C. J. Martin, I. A. Wright, J. A. Zampese, H. J. Bolink and A. Pertegas, Dalton Trans., 2013, 42, 8086-8103.

31 L. He, D. Ma, L. Duan, Y. Wei, J. Qiao, D. Zhang, G. Dong, L. Wang and Y. Qiu, Inorg. Chem., 2012, 51, 4502-4510.

32 S. Kumar, Y. Hisamatsu, Y. Tamaki, O. Ishitani and S. Aoki, Inorg. Chem., 2016, 55, 3829-3843.

33 P. Li, G. G. Shan, H. T. Cao, D. X. Zhu, Z. M. Su, R. Jitchati and M. R. Bryce, Eur. J. Inorg. Chem., 2014, 23762382.

34 C. R. Patrick and G. S. Prosser, Nature, 1960, 187, 1021.

35 V. J. H. Williams, J. K. Cockcroft and N. Fitch, Angew. Chem., 1992, 104, 1666-1669.

36 J. H. Williams, Acc. Chem. Res., 1993, 26, 593-598.

37 A. B. Tamayo, B. D. Alleyne, P. I. Djurovich, S. Lamansky, I. Tsyba, N. N. Ho, R. Bau and M. E. Thompson, J. Am. Chem. Soc., 2003, 125, 7377-7387.

38 A. F. Rausch, M. E. Thompson and H. Yersin, J. Phys. Chem. A, 2009, 113, 5927-5932.

39 S. Berger, S. Braun and H.-O. Kalinowski, NMR Spectroscopy of the Non-Metallic Elements, Wiley, 1st edn, 1997.

40 R. E. Banks and R. N. Haszeldine, J. Chem. Soc., 1967, 1822-1826.

41 E. Klauke, L. Oehlmann and B. Baasner, J. Fluorine Chem., 1982, 21, 495-513.

42 J. Zhou, M. W. Kuntze-Fechner, R. Bertermann, U. S. D. Paul, J. H. J. Berthel, A. Friedrich, Z. Du, T. B. Marder and U. Radius, J. Am. Chem. Soc., 2016, 138, 5250-5253.

43 R. J. Abraham, D. B. Macdonald and E. S. Pepper, J. Am. Chem. Soc., 1968, 90, 147-153.

44 J. Wang, J. Luis, C. Pozo, A. E. Sorochinsky, S. Fustero, V. A. Soloshonok and H. Liu, Chem. Rev., 2014, 114, 24322506.

45 R. Jana, B. Sarkar, D. Bubrin, J. Fiedler and W. Kaim, Inorg. Chem. Commun., 2010, 13, 1160-1162.

46 C. Hansch, A. Leo and R. W. Taft, Chem. Rev., 1991, 91, 165-195. The $\sigma_{\text {meta }}, \sigma_{\text {para }}$ and inductive/field factor $(F)$ values for $\mathrm{C}_{6} \mathrm{~F}_{5}$ and $\mathrm{CF}_{3}$ are $0.26,0.27,0.27$ and $0.43,0.54$, 0.38 , respectively. Therefore, $\mathrm{CF}_{3}$ is expected to be the stronger electron-withdrawing group.

47 A. F. Henwood, A. K. Bansal, D. B. Cordes, A. M. Z. Slawin, I. D. W. Samuel and E. Zysman-Colman, J. Mater. Chem. C, 2016, 4, 3726-3737.

48 V. N. Kozhevnikov, Y. Zheng, M. Clough, H. A. Al-Attar, G. C. Griffiths, K. Abdullah, S. Raisys, V. Jankus, M. R. Bryce and A. P. Monkman, Chem. Mater., 2013, 25, 2352-2358.
49 D. R. Martir, C. Momblona, A. Pertegás, D. B. Cordes, A. M. Z. Slawin, H. J. Bolink and E. Zysman-Colman, ACS Appl. Mater. Interfaces, 2016, 8, 33907-33915.

50 A. M'hamedi, M. A. Fox, A. S. Batsanov, H. A. Al-Attar, A. P. Monkman and M. R. Bryce, J. Mater. Chem. C, 2017, 5, 6777-6789.

51 Calculations predict the structure of meso 11 (Fig. S124†) to be much less folded than rac $\mathbf{1 1}$ (Fig. S125†) and 'rod-like'. This increased aspect ratio may facilitate solid state packing more strongly than for complex 9. DFT gas phase optimised structures in both this study and for previous analogues have been in good agreement with XRD data. $^{21,22}$.

52 S.-Y. Yao, Y.-L. Ou and B.-H. Ye, Inorg. Chem., 2016, 55, 6018-6026.

53 A. M'hamedi, A. S. Batsanov, M. A. Fox, M. R. Bryce, K. Abdullah, H. A. Al-Attar and A. P. Monkman, J. Mater. Chem., 2012, 22, 13529-13540.

54 E. Baranoff, S. Fantacci, F. De Angelis, X. Zhang, R. Scopelliti, M. Grätzel and M. K. Nazeeruddin, Inorg. Chem., 2011, 50, 451-462.

55 J. Frey, B. F. E. Curchod, R. Scopelliti, I. Tavernelli, U. Rothlisberger, M. K. Nazeeruddin and E. Baranoff, Dalton Trans., 2014, 43, 5667-5679.

56 E. Baranoff and B. F. E. Curchod, Dalton Trans., 2015, 44, 8318-8329.

57 J. Li, P. I. Djurovich, B. D. Alleyne, M. Yousufuddin, N. N. Ho, J. C. Thomas, J. C. Peters, R. Bau and M. E. Thompson, Inorg. Chem., 2005, 44, 17131727.

58 G. Li, T. Fleetham, E. Turner, X. C. Hang and J. Li, Adv. Opt. Mater., 2015, 3, 390-397.

59 K. Dedeian, J. Shi, N. Shepherd, E. Forsythe and D. C. Morton, Inorg. Chem., 2005, 44, 4445-4447.

60 T. Fleetham, G. Li, Z. Q. Zhu and J. Li, SID Int. Symp. Dig. Tech. Pap., 2015, 46, 411-414.

61 H. Benjamin, Y. Zheng, A. S. Batsanov, M. A. Fox, H. A. AlAttar, A. P. Monkman and M. R. Bryce, Inorg. Chem., 2016, 55, 8612-8627.

62 E. Baranoff, B. F. E. Curchod, F. Monti, F. Steimer, G. Accorsi, I. Tavernelli, U. Rothlisberger, R. Scopelliti, M. Grätzel and M. K. Nazeeruddin, Inorg. Chem., 2012, 51, 799-811.

63 The $k_{\mathrm{r}}$ values reported here, although comparatively high for sky blue phosphors, are not as high as those of lower energy diiridium emitters. ${ }^{24,26}$ This is not surprising due to the lower MLCT/higher LC character excited states commonly exhibited by blue complexes, evident from their more highly structured emission spectra. ${ }^{65,66}$

64 M. A. Baldo, S. R. Forrest and M. E. Thompson, in Organic Electroluminescence, ed. Z. H. Kafafi, CRC and SPIE Press, 2005.

65 L. Yang, F. Okuda, K. Kobayashi, K. Nozaki, Y. Tanabe, Y. Ishii and M.-A. Haga, Inorg. Chem., 2008, 47, 7154-7165.

66 G. Li, A. Wolfe, J. Brooks, Z. Zhu and J. Li, Inorg. Chem., 2017, 56, 8244-8256. 
67 S. Haneder, E. Da Como, J. Feldmann, J. M. Lupton, C. Lennartz, P. Erk, E. Fuchs, O. Molt, I. Münster, C. Schildknecht and G. Wagenblast, Adv. Mater., 2008, 20, 3325-3330.

68 C.-H. Yang, M. Mauro, F. Polo, S. Watanabe, I. Muenster, R. Frohlich and L. De Cola, Chem. Mater., 2012, 24, 36843695.

69 T. Duan, T.-K. Chang, Y. Chi, J.-Y. Wang, Z.-N. Chen, W.-Y. Hung, C.-H. Chen and G.-H. Lee, Dalton Trans., 2015, 44, 14613-14624.

70 H. J. Park, J. N. Kim, H. Yoo, K. Wee, S. O. Kang and D. W. Cho, J. Org. Chem., 2013, 78, 8054-8064.
71 T. B. Fleetham, L. Huang, K. Klimes, J. Brooks and J. Li, Chem. Mater., 2016, 28, 3276-3282.

72 G. Nasr, A. Guerlin, F. Dumur, L. Beouch, E. Dumas, G. Clavier, F. Miomandre, F. Goubard, D. Gigmes, D. Bertin, G. Wantz and C. R. Mayer, Chem. Commun., 2011, 47, 10698-10700.

73 F. Lafolet, S. Welter, Z. Popović and L. De Cola, J. Mater. Chem., 2005, 15, 2820-2828.

74 R. D. Costa, G. Fernandez, L. Sanchez, N. Martín, E. Ortí and H. J. Bolink, Chem. - Eur. J., 2010, 16, 9855-9863.

75 X. Yang, X. Xu, J. Dang, G. Zhou, C.-L. Ho and W.-Y. Wong, Inorg. Chem., 2016, 55, 1720-1727. 